\title{
Quantitative Study on Empirical Strength Parameters of Extremely Fractured Phyllite Based on Fractal Theory
}

\author{
Yongbin Xie $\mathbb{D}^{D}$, Xiaoyu Yang $(\mathbb{D}$, Jianhua Dong $(\mathbb{D}$, and Guosheng Liu \\ Western Centre of Disaster Mitigation in Civil Engineering, Ministry of Education, Lanzhou University of Technology, \\ Lanzhou 730050, China \\ Correspondence should be addressed to Jianhua Dong; djhua512@163.com
}

Received 8 July 2021; Accepted 12 August 2021; Published 18 August 2021

Academic Editor: Bo Li

Copyright (c) 2021 Yongbin Xie et al. This is an open access article distributed under the Creative Commons Attribution License, which permits unrestricted use, distribution, and reproduction in any medium, provided the original work is properly cited.

Extremely broken phyllite is widely distributed and is easily seen in engineering construction. Aiming at the problem that the empirical strength parameters of extremely broken surrounding rock have intense subjectivity and significant difference, based on the characteristics of the existence of particle group state in the highly broken surrounding rock, the fractal theory and large-scale direct shear test are used, the fractal description of polar broken phyllite samples with different pile numbers in fault fracture zone of Qinyu Tunnel is carried out, and the fractal dimensions and empirical strength parameters of each sample are determined. Based on a fractal description and large shear test, the functional relationship between fractal dimension and empirical strength parameter of extremely broken phyllite in fault fracture zone is established, and the quantitative value method of empirical strength parameter determined by fractal dimension of extremely broken phyllite is given, which provides ideas for the quantitative value of empirical strength parameter of the similar extremely broken surrounding rock.

\section{Introduction}

Rock mass strength criterion is the basis for judging whether it is damaged in theory and an important basis for engineering design. Generally, the accuracy of relevant empirical parameters in the strength criterion is the most important factor to determine whether the rock mass strength criterion is reasonable. Therefore, in engineering design practice, reasonably and accurately determining the relevant empirical parameters of rock mass strength criterion is the basis of its wide application. The Hoek-Brown strength criterion is a combination of rock theoretical research results and many test results statistics. Its simplicity and practicability have been widely accepted by the engineering geological circles. It is the most widely used and influential rock strength criterion so far, and it is also a method recommended by the international society of rock mechanics [1-4]. The envelope of the Hoek-Brown strength criterion is parabola, which can describe the nonlinear failure characteristics of rock mass. The essence of the strength criterion is to attribute all factors affecting the strength characteristics of rock mass to two empirical strength parameters $m$ and $s$, so the value of empirical parameters $m$ and $s$ of rock mass will play a decisive role in the accuracy of the strength criterion $[5,6]$. It is of great scientific value to apply the Hoek-Brown strength criterion to study the quantitative value of rock mass empirical parameters.

The empirical parameters $m$ and $s$ of the Hoek-Brown strength criterion are mainly determined by laboratory test and field estimation [7-9]. The empirical parameters determined by the indoor test method are relatively accurate, but there are some shortcomings, such as long cycle, high cost, and large size effect [10-12]. Field estimation is a method to establish a quantitative relationship between rock mass quality evaluation index and empirical parameters by comprehensively considering many factors affecting rock mass strength. Its process is simple and practical. RMR rock mass scoring system and GSI field rock mass quality classification method have been widely used $[13,14]$. However, the RMR rock mass scoring system is not suitable for broken rock mass, so GSI geological strength index is the most widely used empirical strength parameter value method [15]. 
Sonmez and Ulusay [16] have given the GSI value table, which can consider the distribution of discontinuities, roughness, and filling materials. Cai et al. [17] proposed a method to determine GSI by using the block's volume and the structural surface parameters. Jiang et al. [18] introduced the rock mass fragmentation index to determine the number of rock mass volume joints and rock mass structure grade and used the above parameters to determine the GSI value of rock mass. It can be seen from the above research that there are many factors influencing the GSI value of the geological strength index, which is mainly based on the structural characteristics and structural surface characteristics of the rock mass, and the value is highly subjective. The extremely broken surrounding rock is formed by the continuous expansion and connection of the total rock mass in the random distribution of initial defects under external load, weathering, and other factors. It is mainly in particle group, and it is difficult to determine the above characteristics of the rock mass accurately. Therefore, the value of GSI for the extremely broken surrounding rock has certain randomness. For the same surrounding rock, the values of empirical parameters are quite different.

The extremely broken phyllite in the Qinyu Tunnel is the rock fragment and gravel torn from the phyllite fault wall after the relative movement of the two walls of the fault. Its main mineral combination is sericite, chlorite, and quartz, containing a small amount of feldspar, carbonaceous, and iron, and its engineering properties are very poor. If the strength characteristics of the extremely broken phyllite cannot be accurately evaluated in the tunnel construction, it is very prone to engineering geological disasters. Therefore, in order to accurately give the empirical strength parameters of the Hoek-Brown strength criterion for extremely broken phyllite, based on the theory that broken rock blocks may show fractal distribution characteristics in a statistical sense, the field samples of extremely broken phyllite in different positions of fault fracture zone are taken, the fractal distribution characteristics of highly broken phyllite in fault fracture zone are verified by a screening test, and the fractal dimension quantitative indexes representing the characteristics of extremely broken phyllite in different positions are obtained. Based on the laboratory large-scale shear test, the empirical strength parameters of the highly fractured phyllite at different positions of the fault fracture zone are determined, and the functional relationship between the empirical strength parameters and fractal dimension of the extremely fractured phyllite is established. The empirical strength parameters of the Hoek-Brown strength criterion are determined by using the quantitative parameters in fractal theory, which provides ideas and methods for the quantitative value of the empirical parameters of the extremely fractured phyllite at similar fault fracture zones.

\section{Sampling and Fractal Description of Extremely Fractured Phyllite}

The test sample comes from the fault fracture zone of ZK345 + 735 ZK346+660 section of the Qinyu Tunnel. The sampling point of sample $\mathrm{I}$ is near the interface between hanging wall and fracture zone, and the pile number is ZK345 + 740. The sampling point of sample II is near the stake ZK345 + 965. The sampling point of sample III is located in the middle of the fracture zone, and the pile number is ZK346+120. The sampling point of sample IV is near $\mathrm{ZK} 346+350$. The sampling point of sample $\mathrm{V}$ is located near the interface between footwall and fracture zone, and the pile number is ZK346+650. When sampling on-site, it can be seen that the rock mass in the fracture zone is greyish-black, with loose structure, good grading, and angular shape. The general particle size is $2-4 \mathrm{~cm}$, and the maximum visible particle size is $8-15 \mathrm{~cm}$. The sampling position and extremely broken phyllite on-site are shown in Figure 1.

After sampling, the rock samples are put into plastic bags, wrapped with preservative film, and sealed in prefabricated wooden cases. Labels are pasted on the wooden cases to note the sampling position. Screening tests are carried out for extremely broken phyllite at each sampling point in laboratory. The representative grading of each sampling point is shown in Table 1 .

The fractal relation of broken rock is usually defined by particle size and its quantity relationship. However, the number of particles in the broken rock is large, and the distribution range of particle size is vast. It is difficult to establish the fractal model of the particle size by existing test methods. Tyler et al. $[19,20]$ propose to describe the fractal characteristics of broken rock by the mass distribution of particle size, whose formula is as follows:

$$
\frac{M\left(d \geq d_{i}\right)}{M_{T}}=1-\left(\frac{d_{i}}{\beta}\right)^{3-D},
$$

where $d$ is the particle size of broken particles, $d_{i}$ is the particle size of a grading particle, $M\left(d \geq d_{i}\right)$ is the mass of particles larger than the particle size $d_{i}$ in the sample, $M_{T}$ is the total mass of the sample, $\beta$ is the coefficient related to the shape and size range of broken particles, and $D$ is the fractal dimension, which is the quantitative parameter of fractal geometry to characterize the properties of broken surrounding rock.

When it is the statistical maximum particle size $d_{i}$, i.e., $d_{i}=d_{\max }$, it is simplified by formula (1), and the correlation coefficient characterizing the size range of broken surrounding rock is

$$
\beta=d_{\max }
$$

By taking equation (2) into equation (1), we can get the following results:

$$
\left(\frac{d_{i}}{d_{\max }}\right)^{3-D}=\frac{M\left(d<d_{i}\right)}{M_{T}} .
$$

Take logarithm on both sides of equation (3). If the logarithm $d_{i} / d_{\max }$ and logarithm $M\left(d<d_{i}\right) / M_{T}$ of each sample can show an excellent linear relationship, it can be considered that the sample shows exemplary distribution fractal characteristics, and the fractal dimension of the broken surrounding rock sample can be obtained. 


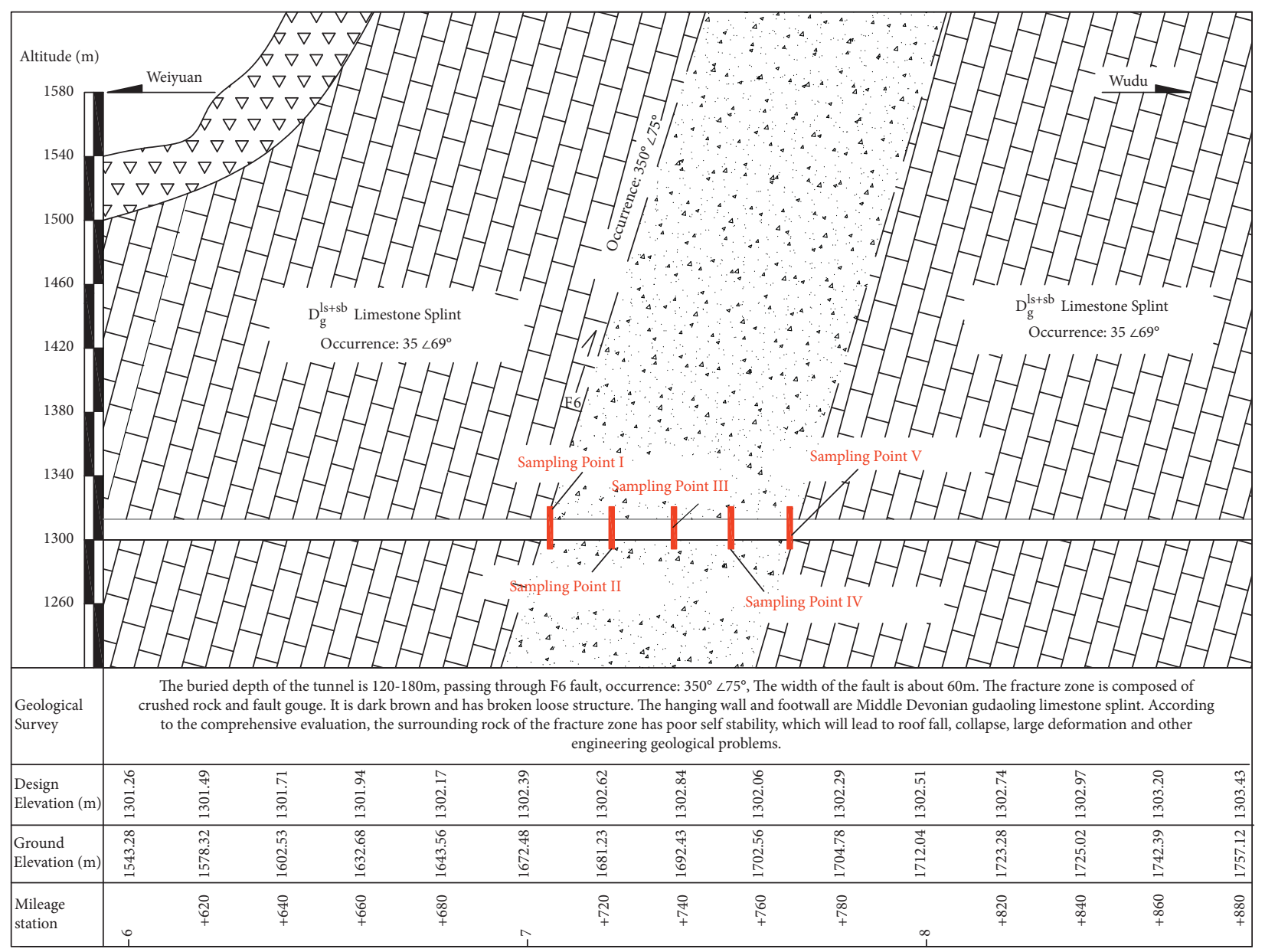

(a)

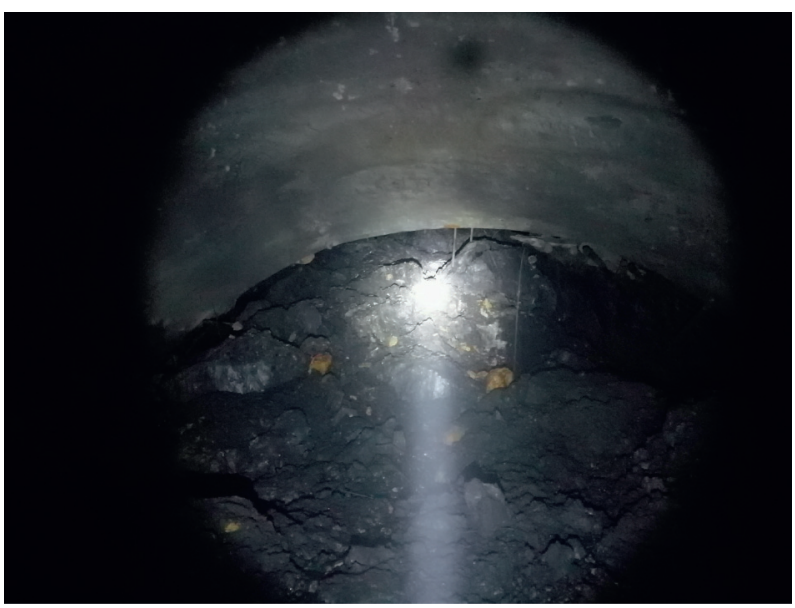

(b)

FIGURE 1: Location of sampling points and diagram of extremely fractured phyllite. (a) Schematic diagram of sampling point location. (b) Site photos of extremely fractured phyllite. 
TABLE 1: Representative gradation of different sampling points.

\begin{tabular}{lcccccccc}
\hline \multirow{2}{*}{ Sample } & \multicolumn{7}{c}{ Composition of representative graded particles (\%) } \\
& $150 \sim 80 \mathrm{~mm}$ & $80 \sim 60 \mathrm{~mm}$ & $60 \sim 40 \mathrm{~mm}$ & $40 \sim 20 \mathrm{~mm}$ & $20 \sim 10 \mathrm{~mm}$ & $10 \sim 5 \mathrm{~mm}$ & $5 \sim 0.1 \mathrm{~mm}$ & $<0.1 \mathrm{~mm}$ \\
\hline I & 0.0 & 10.2 & 12.9 & 27.4 & 10.8 & 12.7 & 16.7 \\
II & 5.1 & 12.8 & 23.3 & 23.4 & 14.3 & 5.8 & 10.9 \\
III & 7.5 & 13.6 & 14.1 & 29.2 & 18.8 & 9.7 & 4.4 \\
IV & 2.0 & 15.3 & 17.8 & 22.7 & 18.2 & 8.2 & 14.3 \\
V & 0.0 & 5.3 & 10.9 & 21.5 & 24.8 & 9.5 & 1.3 \\
\hline
\end{tabular}

$$
D=3-k \text {, }
$$

where $k$ is the slope of curve fitting with the logarithm of $d_{i} / d_{\max }$ and $M\left(d<d_{i}\right) / M_{T}$ as abscissa and ordinate.

According to the particle grading table of samples at fault fracture zone of different pile numbers in Table 1, the fractal curve of each sample is drawn, as shown in Figure 2.

It can be seen from the fractal curve of each sample in Figure 2 that the fractal curve of grain size distribution of extremely fractured phyllite samples with different pile numbers in fault fracture zone is approximately a straight line, and the correlation coefficient is more significant than 0.95 after fitting the straight line to each data point. The fractal dimension can be used as a quantitative index to characterize the grain size characteristics of the highly fractured phyllite. It is feasible to evaluate the grain size characteristics of the extremely fractured surrounding rock by using the fractal dimension. The slope of the fitting line is brought into equation (4) to obtain the fractal dimension of samples with different pile numbers in the fault fracture zone, as shown in Table 2.

According to Table 2, the correlation coefficients are close to 1 , so the extremely broken surrounding rock in the fault fracture zone can show good fractal characteristics, and its fractal dimension varies from 2.154 to 2.643 . The fractal dimension of sample $\mathrm{V}$ is the largest. Compared with the sample gradation in Table 1, it is found that the content of fine aggregate with particle size less than $5 \mathrm{~mm}$ is the most. The fractal dimension of sample III is the smallest. Comparing with the sample gradation in Table 1, it is found that the content of fine material with particle size less than $5 \mathrm{~mm}$ is the least. In addition, by comparing the fractal dimension and acceptable particle content of each sample, it is found that the smaller the fine particle content in the sample, the smaller the fractal dimension of the sample, and the fractal dimension value is closely related to the particle gradation of the sample. For the same kind of broken surrounding rock, the grain gradation is the most critical factor affecting the strength of rock mass, and the fractal dimension can well reflect the grain characteristics of the extremely broken surrounding rock, so it is feasible to establish the relationship between fractal dimension and strength parameters.

\section{Determination of Empirical Strength Parameters Based on Large-Scale Shear Test}

In order to establish the relationship between fractal dimension of extremely fractured phyllite and empirical strength parameters, it is necessary to determine the empirical strength parameters accurately. The large-scale direct shear test is the most commonly used indoor test method to accurately determine the empirical parameters of rock mass. In this paper, the empirical strength parameters of extremely fractured phyllite at different pile numbers in fault fracture zone are determined by large-scale direct shear tests.

3.1. Shearing Instrument and Sample Handling. The test was performed with a large direct shearing apparatus manufactured by GEOCOMP, USA, as shown in Figure 3. The direct shearing instrument mainly includes displacement sensor, load sensor, loading system, support, shear box, limit switch, intelligent control system, and measuring system. The shearing instrument and measuring system transmit data during the test through the network connection. The loading system is a stepper motor, which is fixed in the vertical and horizontal directions of the support, respectively. The cutting box cavity is cuboid, size $305 \mathrm{~mm} \times 305 \mathrm{~mm} \times 200 \mathrm{~mm}$ (long) $\times$ wide $\times$ high), the upper shear box is fixed, but vertical stress can be applied in the vertical direction, and the lower shear box can move horizontally under thrust. The intelligent control system controls the horizontal movement of the lower shear box at a fixed shear rate while maintaining constant vertical stress at the top of the upper shear box.

When carrying out large-scale indoor shear tests, the size of the shear box is fixed. If the size of the sample directly used in the field is limited by the size, the test data will be distorted. Therefore, the oversize should be treated before the test is carried out. Determine the maximum allowable sample material diameter of $60 \mathrm{~mm}$ according to the shear box size. The equivalent substitution method is to distribute the superparticle content in the sample to each gradation with the maximum allowable particle size and the $5 \mathrm{~mm}$ particle size utilizing the weighted average method. The superparticle can be processed without changing the coarse particle content. It is suitable for samples with less than or equal to $50 \%$ content with the superparticle content [21]. Superparticle sizes of samples I V can be well treated. The particle size content of each sample after modification of superparticle size is calculated as follows:

$$
\begin{aligned}
& P_{5 i}=\frac{P_{5}}{P_{5}-P_{0}} P_{05 i}, \\
& P_{5}=\sum_{1}^{n} P_{5 i}=\sum_{1}^{n} P_{05 i}+P_{0},
\end{aligned}
$$




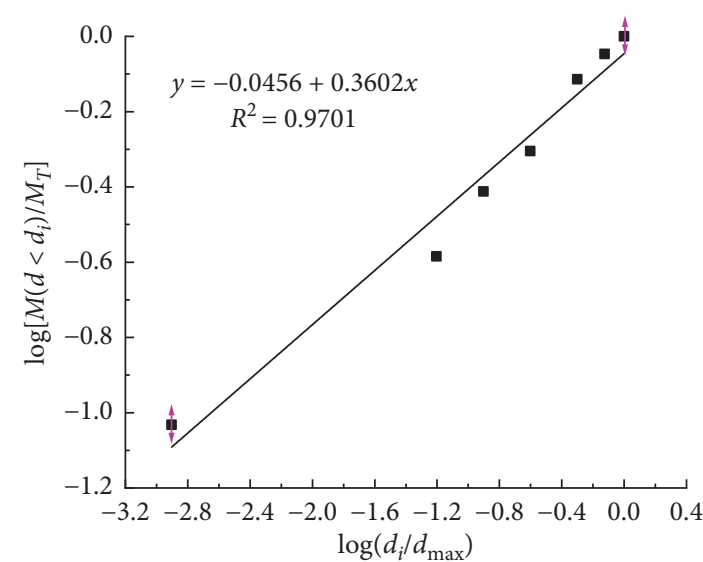

(a)

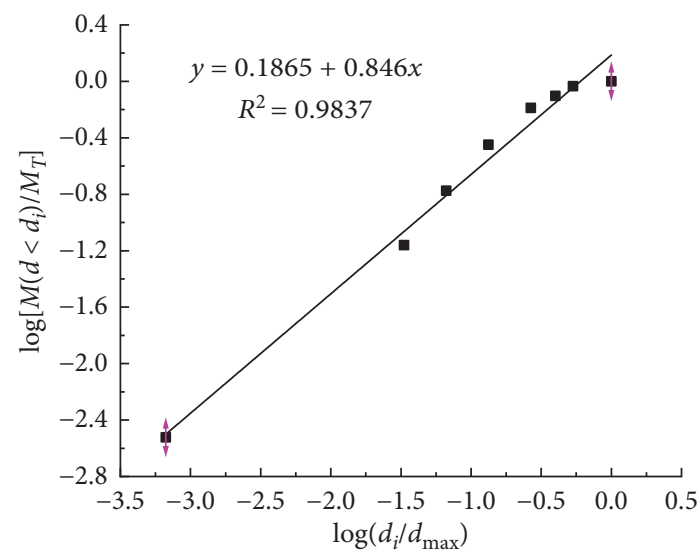

(c)

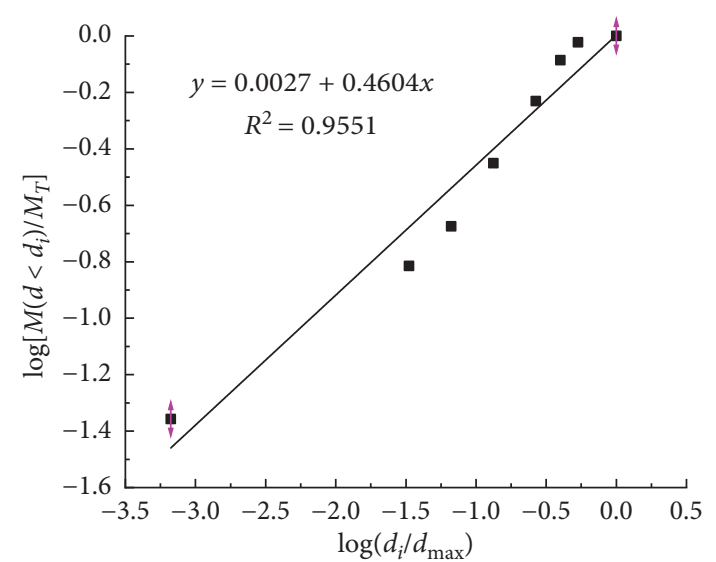

(b)

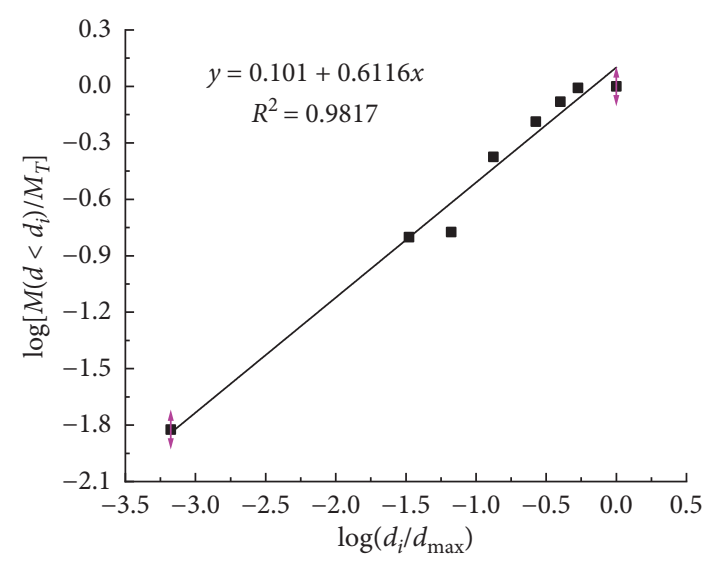

(d)

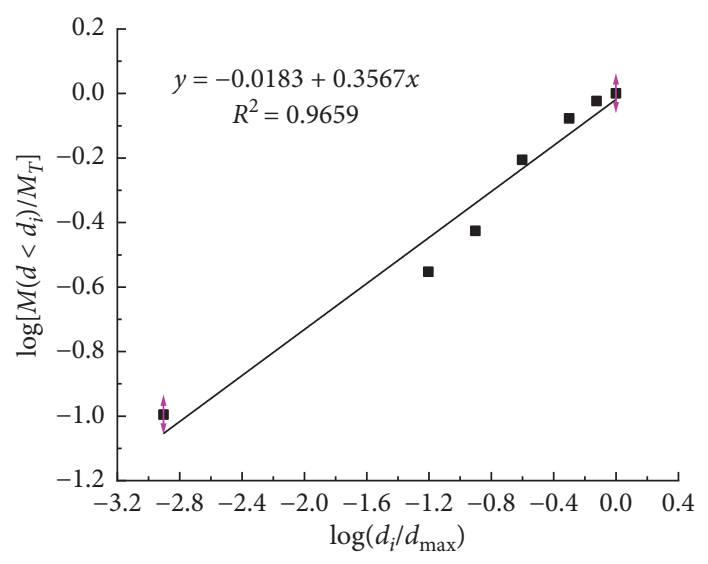

(e)

Figure 2: Fractal curve of particle size distribution of samples with different pile numbers in fault fracture zone. Fractal curve of particle size distribution of (a) sample I, (b) sample II, (c) sample III, (d) sample IV, and (e) sample V.

where $P_{0}$ is the content percentage of sample superparticle size, $P_{5}$ is the percentage of sample with particle size larger than $5 \mathrm{~mm}, P_{5 i}$ is the percentage of particle size greater than $5 \mathrm{~mm}$ after distribution by the weighted average method, and $P_{05 i}$ is the content percentage of each grade particle size of the original sample.

Based on the grading of each sample in Table 1, formulas (5) and (6) are used to treat the ultraparticle size of extremely fractured phyllite samples of each pile number in the fault fracture zone. The grading of each sample before and after treatment is shown in Figure 4.

3.2. Large Shear Test Process and Results. Prepare the samples according to the grading characteristics after ultraparticle treatment in Figure 4. Remove the upper and lower shear 
TABLE 2: Fractal dimension values and correlation coefficients of different samples.

\begin{tabular}{lcc}
\hline Sample name & Fractal dimension $D$ & Correlation coefficient $R^{2}$ \\
\hline Sample I & 2.640 & 0.9701 \\
Sample II & 2.540 & 0.9551 \\
Sample III & 2.154 & 0.9837 \\
Sample IV & 2.338 & 0.9817 \\
Sample V & 2.643 & 0.9659 \\
\hline
\end{tabular}

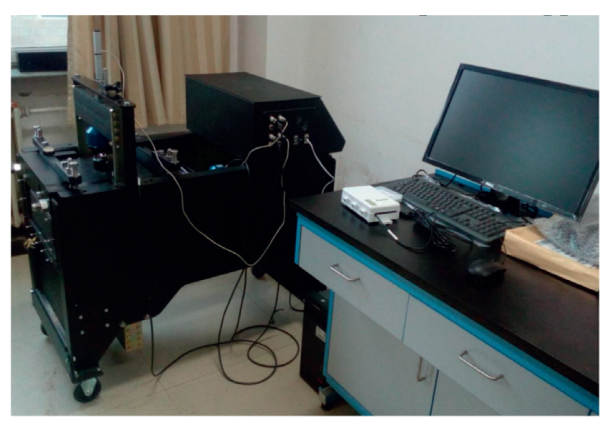

(a)

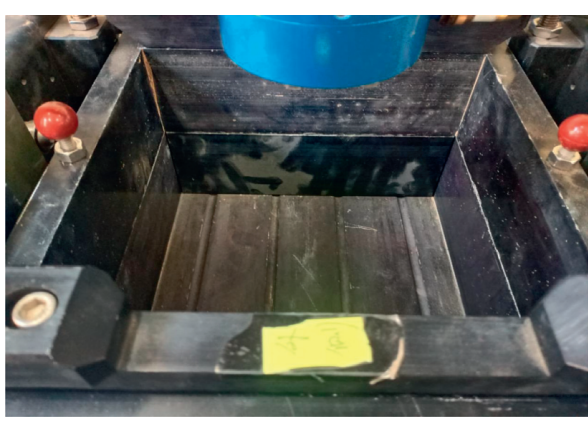

(b)

FIgURE 3: Large direct shearing instrument. (a) Large direct scissor photos. (b) Upper and lower shear boxes.

boxes, place them on the support frame, fix the upper and lower shear boxes, and sample layers by layers. In order to prevent uneven distribution of coarse and fine particles of the sample, rough classification of coarse and fine particles was carried out with $5 \mathrm{~mm}$ as the limit before the sample was poured into the shear box. According to the height of the shear box, each sample filling will be completed 3 times, and each filling height is about $60 \mathrm{~mm}$. Fill and divide the coarse and fine particles into three equal parts. First, pour in one coarse particle material, and then pour in another fine particle material. Mix evenly and remove the large particle size on the surface. Then, hammer it down with rubber. Repeat the above steps to start the second filling until the sample filling is complete. After filling the sample, install the shear box, start the loading system of the shearing apparatus, and make sure that the load sensor is cleared without contact with the rest of the shearing apparatus. The normal stress was applied according to the designed load condition. After the numerical value of the normal stress was stabilized, the upper shear box was slightly lifted by the front and rear beams on the shear box, and the bolts fixing the upper and lower shear boxes were removed. The shear test began at a loading rate of $2 \mathrm{~mm} / \mathrm{min}$ with the normal stress unchanged. Figure 5 shows the filling and shearing process of some specimens.

Figure 6 shows the shear stress and shear displacement curves of each specimen of extremely fractured phyllite at each fault fracture zone under normal stress conditions of $100 \mathrm{kPa}, 150 \mathrm{kPa}, 200 \mathrm{kPa}, 250 \mathrm{kPa}$, and $300 \mathrm{kPa}$.

It can be seen from the diagram that, under different normal stress conditions, the shear stress of each sample increases gradually with the increase of shear displacement. When the shear displacement is between $40 \mathrm{~mm}$ and $50 \mathrm{~mm}$, the shear stress of each sample starts to reach its peak value.
Continue the shear test until the shear displacement reaches $80 \mathrm{~mm}$, and the shear stress of each sample will gradually decrease, which may be the influence of the increase of shear displacement and the decrease of shear area. The particle size distributions of samples 1 and 5 are close, and the maximum shear stress values under different normal stress conditions are close. Particle size distributions of sample 2 and sample 4 are close, and their maximum shear stress values under different normal stresses are also close. The coarse particle content of sample 3 is higher than that of other samples. By comparing the maximum shear stress values under different normal stress conditions, it can be seen that the shear stress of sample 3 is higher than that of other samples under the same normal stress conditions. It shows that particle size is the most important factor affecting the strength of materials in extremely fractured surrounding rocks composed of the same material.

3.3. Determination of Empirical Strength Parameters for Each Sample. The empirical strength criterion of rock mass is formed by statistics of many test data to overcome the defect of the theoretical strength criterion. The empirical strength criterion put forward by E. Hoek and E. T. Brown in 1980 is the most widely used one, which can be applied to complete or broken jointed rock mass [2]. Its expression is

$$
\sigma_{1}=\sigma_{3}+\sigma_{c}\left(m \frac{\sigma_{3}}{\sigma_{c}}+s\right)^{0.5}
$$

where $\sigma_{1}$ is the maximum principal stress of rock mass failure, $\sigma_{3}$ is the minimum principal stress of rock mass failure, $\sigma_{c}$ is the uniaxial compressive strength of rock block, $m$ and $s$ are both empirical parameters of rock mass, $m$ mainly reflects the degree of hardness and softness of rock, 


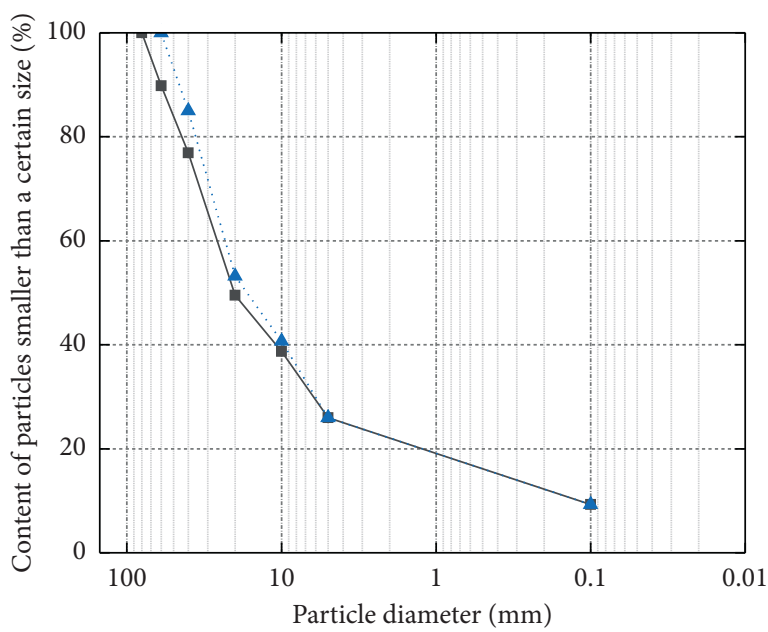

- Particle size distribution of original sample

A. . Particle size distribution after replacement treatment

(a)

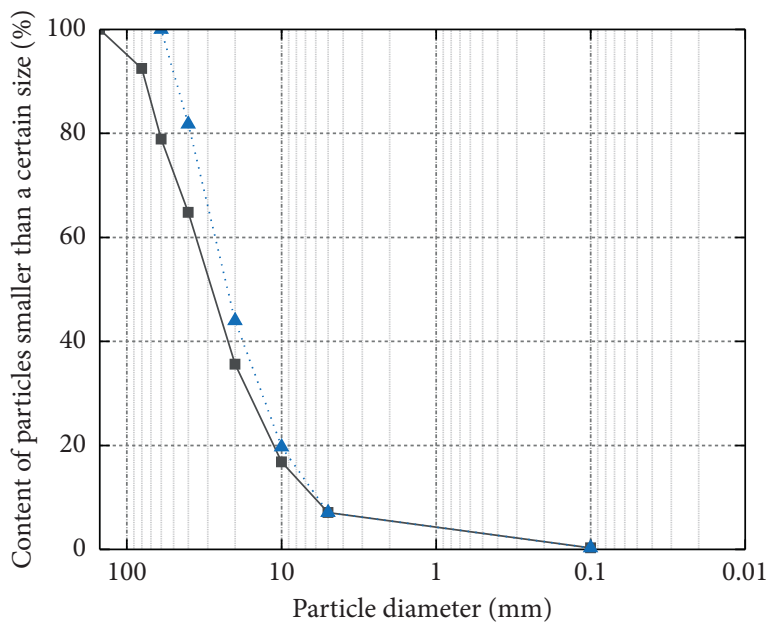

- Particle size distribution of original sample

- . Particle size distribution after replacement treatment

(c)

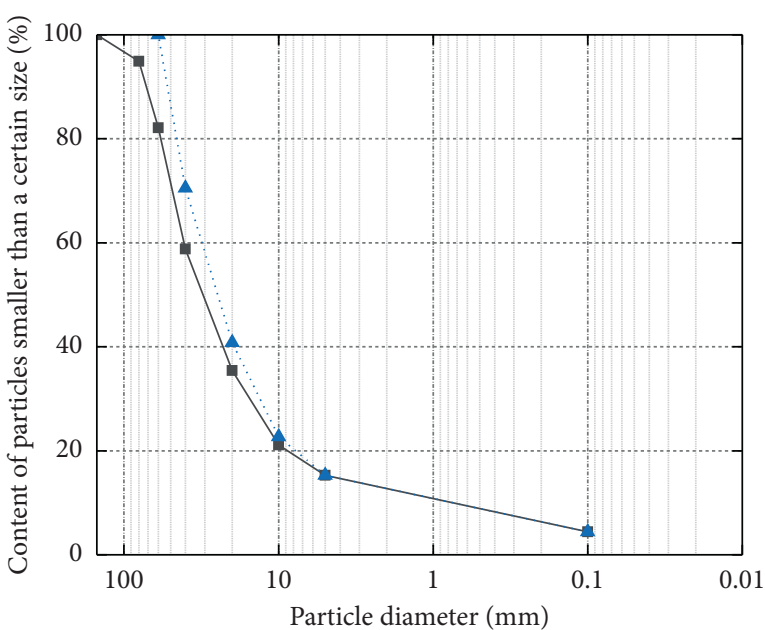

- Particle size distribution of original sample

A. . Particle size distribution after replacement treatment

(b)

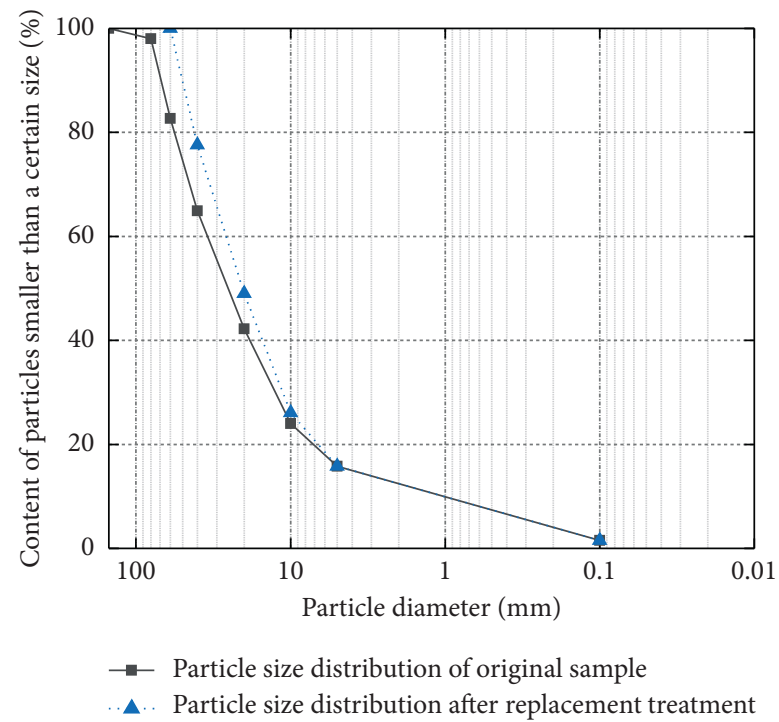

(d)

Figure 4: Continued. 


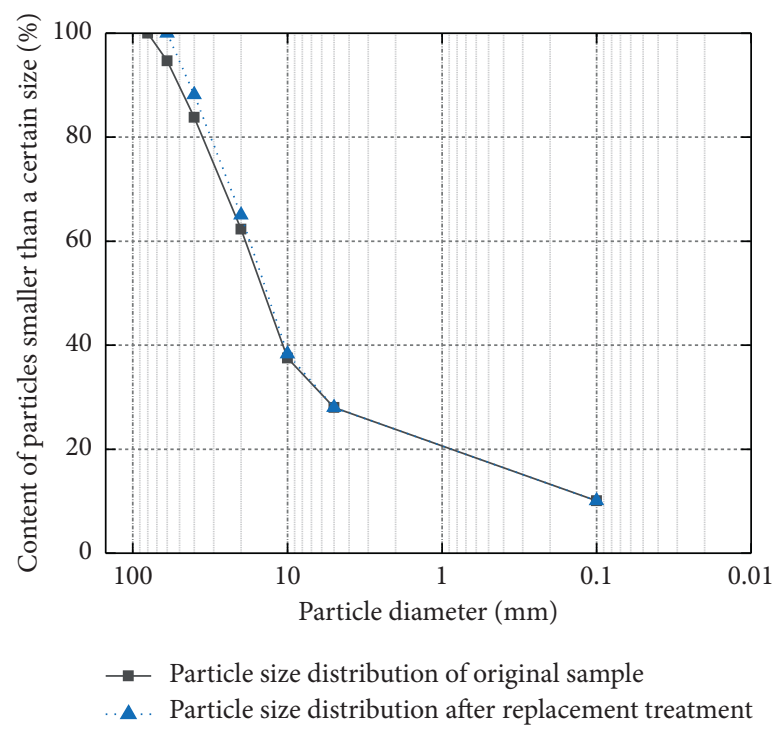

(e)

FIGURE 4: Gradation curves before and after treatment of superparticle size of piles in fault fracture zone. (a) Gradation curve of sample I before and after superparticle treatment. (b) Gradation curve of sample II before and after superparticle treatment. (c) Gradation curve of sample III before and after superparticle treatment. (d) Gradation curve of sample IV before and after superparticle treatment. (e) Gradation curve of sample $\mathrm{V}$ before and after superparticle treatment.

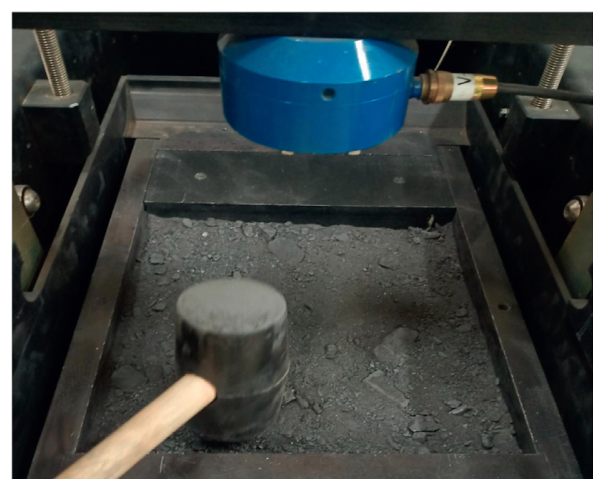

(a)

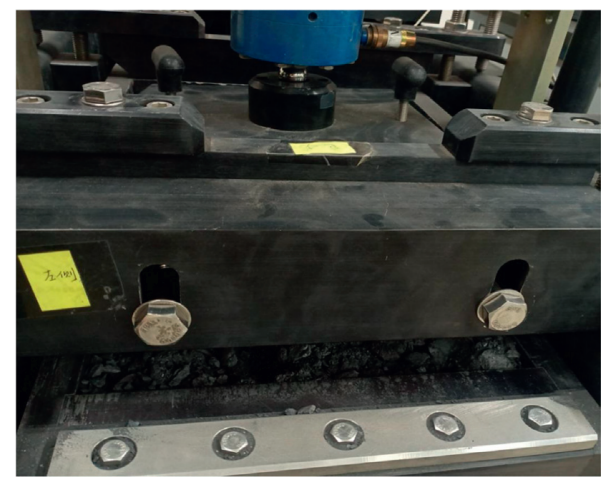

(b)

FIGURE 5: Filling and shear process photographs of extremely fractured phyllite samples at fault fracture zone. (a) Photos of surface leveling and filling of extremely broken phyllite samples. (b) Photos of shear process of extremely fractured phyllite samples.

and the value range is usually between 0.0000001 and 25, and $s$ reflects the fragmentation degree of rock mass, and the value range is between 0 and 1 .

When the empirical parameters $m$ and $s$ are determined by large shear test statistics, the expression of equation (7) is transformed. At this time, the relationship between the empirical parameters and the maximum and minimum principal stresses is as follows:

$$
\left(\frac{\sigma_{1}-\sigma_{3}}{\sigma_{c}}\right)^{2}=m \frac{\sigma_{3}}{\sigma_{c}}+s .
$$

According to Balmer's deduction hypothesis [2], the stress of the material in the limit state satisfies Mohr's circle equation, and the relationship is as follows:

$$
\left(\frac{\sigma_{1}+\sigma_{3}}{2}-\sigma\right)^{2}+\tau^{2}=\left(\frac{\sigma_{1}-\sigma_{3}}{2}\right)^{2}
$$

The maximum and minimum principal stress, shear stress, internal friction angle, and normal stress are as follows:

$$
\begin{aligned}
& \sigma_{1}=\sigma+\tau \frac{1-\cos (90+\phi)}{\sin (90+\phi)}, \\
& \sigma_{3}=\sigma-\tau \frac{1+\cos (90+\phi)}{\sin (90+\phi)},
\end{aligned}
$$

where $\sigma$ and $\tau$ are the normal stress and shear stress obtained from the shear test and $\phi$ is the corresponding internal friction angle. 


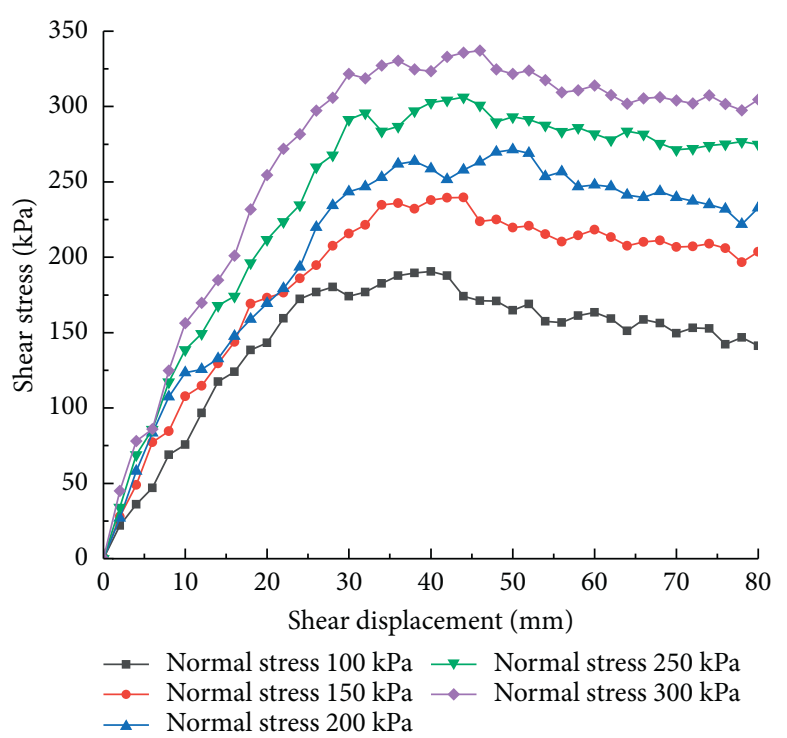

(a)

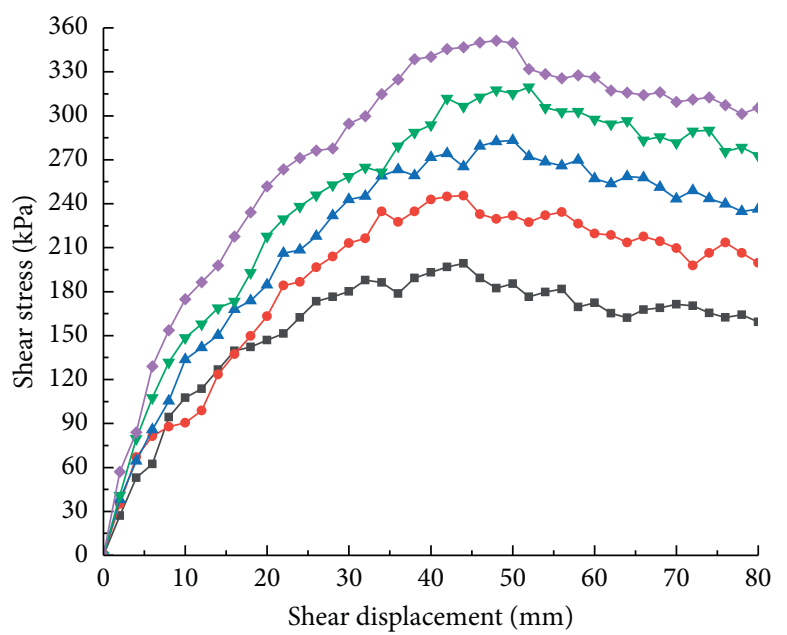

$\rightarrow$ Normal stress $100 \mathrm{kPa} \rightarrow$ Normal stress $250 \mathrm{kPa}$ $\rightarrow$ Normal stress $150 \mathrm{kPa} \longrightarrow$ Normal stress $300 \mathrm{kPa}$ $\neg$ Normal stress $200 \mathrm{kPa}$

(c)

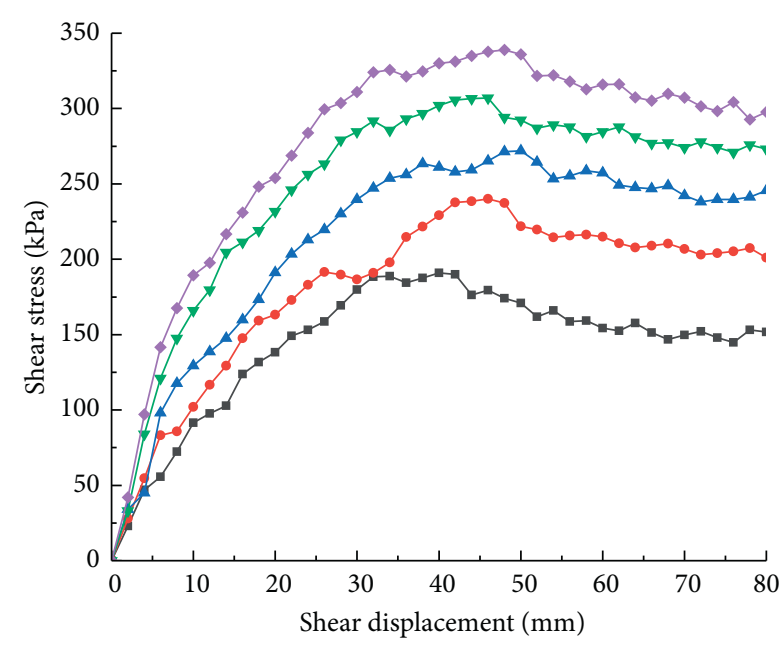

$\rightarrow$ Normal stress $100 \mathrm{kPa} \rightarrow$ Normal stress $250 \mathrm{kPa}$

$\rightarrow$ Normal stress $150 \mathrm{kPa} \rightarrow$ Normal stress $300 \mathrm{kPa}$ $\neg$ Normal stress $200 \mathrm{kPa}$

(b)

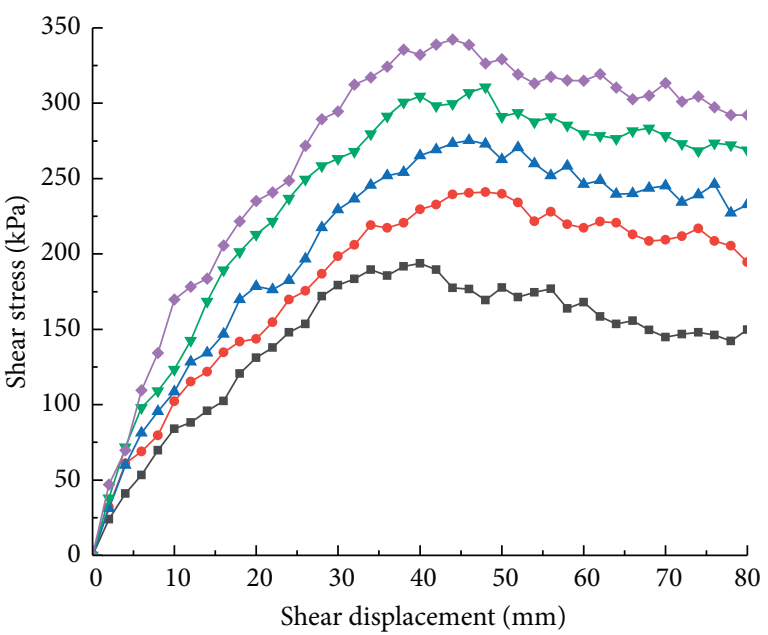

$\rightarrow$ Normal stress $100 \mathrm{kPa} \rightarrow$ Normal stress $250 \mathrm{kPa}$

$\rightarrow$ Normal stress $150 \mathrm{kPa} \rightarrow$ Normal stress $300 \mathrm{kPa}$

$\neg$ Normal stress $200 \mathrm{kPa}$

Figure 6: Continued. 


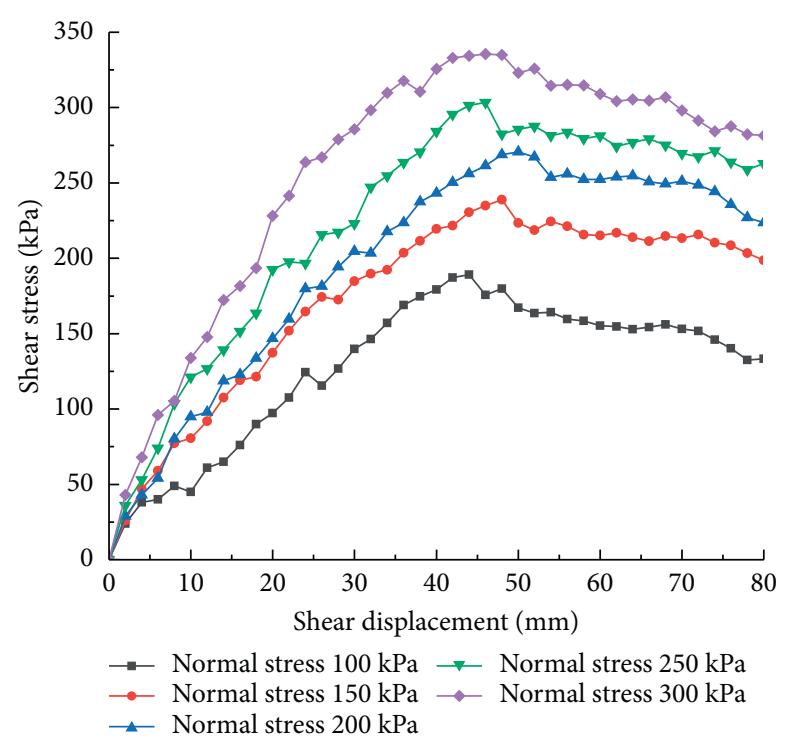

(e)

FiguRE 6: Shear stress-shear displacement curves of each sample under different normal stress conditions. (a) Sample I shear stress-shear displacement curve. (b) Sample II shear stress-shear displacement curve. (c) Sample III shear stress-shear displacement curve. (d) Sample IV shear stress-shear displacement curve. (e) Sample V shear stress-shear displacement curve.

Taking the maximum shear stress during the direct shear test of each sample as the shear strength of each sample, according to the test results in Figure 6, the maximum and minimum principal stresses of each sample under the limit state under different normal forces can be obtained, as shown in Table 3.

For the uniaxial compressive strength $\sigma_{c}=21 \mathrm{MPa}$ of phyllite blocks, the empirical parameters $m$ and $s$ can be fitted according to the functional relation of equation (8) by calculating the maximum and minimum principal stresses from each sample. The fitting results are shown in Figure 7.

It can be seen from the diagram that the linear function relation of equation (8) can be used to fit the test results obtained from the shear test. The slope of the fitted line is the empirical constant $m$ of each sample, and the constant term of the line is the empirical parameter $s$, as shown in Table 4.

\section{Establishment of Relationship between Fractal Dimension and Strength Empirical Parameters of Extremely Fractured Phyllite}

According to the corresponding fractal dimensions and experience parameters of each sample in Tables 2 and 4, the fractal dimensions and experience constants $D \sim m$ and $D \sim s$ of each sample are plotted in a rectangular coordinate system, and the relationship fitting is carried out, as shown in Figure 8.

Figure 8 shows the relationship between the fractal dimension $D$ of each sample and the empirical strength parameters $m$ and $s$. It can be seen from the diagram that the empirical strength parameters $m$ and $s$ decrease with the increase of the fractal dimension of the sample, and there is a significant correlation between the fractal dimension $D$ and the empirical strength parameters. The regression analysis method shows that the linear relationship mainly exists for the empirical parameters $s$ and the fractal dimension $D$, which can be expressed as

$$
s=a_{s}+b_{s} D
$$

where $D$ is the fractal dimension of extremely broken surrounding rock and $a_{s}$ and $b_{s}$ are the test constants related to the lithology of fractured surrounding rock. For the extremely fractured phyllite in the fault fracture zone of this paper, $a_{s}$ is taken as 0.00085 and $b_{s}$ is taken as -0.00013 .

For the empirical parameter $m$ and fractal dimension $D$, they can show exponential correlation, so the empirical parameter $m$ and fractal dimension $D$ can be expressed as follows:

$$
m=a_{n} D^{b_{n}}
$$

where $D$ is the fractal dimension of extremely broken surrounding rock and $a_{n}$ and $b_{n}$ are the test constants related to the grain and lithology of the fractured surrounding rock. For the extremely fractured phyllite in the fracture zone of this paper, $a_{n}$ is taken as 0.3422 and $b_{n}$ is taken as -0.712 .

In conclusion, the fractal dimension of fractal quantification parameter can be determined for extremely fractured phyllite at fault fracture zone according to screening test and fractal theory. The empirical strength parameters are determined by combining formulas (11) and (12) using the high correlation between fractal dimension and empirical strength parameters. It not only solves the shortcomings of long period and high cost of indoor test but also solves the problem that geological strength index is greatly influenced by human factors, and its value is highly subjective. 
TABLE 3: Maximum and minimum principal stresses of each specimen under different normal stresses $(\mathrm{kPa})$.

\begin{tabular}{|c|c|c|c|c|c|c|c|c|c|c|}
\hline \multirow[t]{2}{*}{ Sample name } & \multicolumn{2}{|c|}{$\begin{array}{c}\text { Normal stress } \\
p=100 \mathrm{kPa}\end{array}$} & \multicolumn{2}{|c|}{$\begin{array}{c}\text { Normal stress } \\
p=150 \mathrm{kPa}\end{array}$} & \multicolumn{2}{|c|}{$\begin{array}{c}\text { Normal stress } \\
p=200 \mathrm{kPa}\end{array}$} & \multicolumn{2}{|c|}{$\begin{array}{c}\text { Normal stress } \\
250 \mathrm{kPa}\end{array}$} & \multicolumn{2}{|c|}{$\begin{array}{c}\text { Normal stress } \\
p=300 \mathrm{kPa}\end{array}$} \\
\hline & $\sigma_{1}$ & $\sigma_{3}$ & $\sigma_{1}$ & $\sigma_{3}$ & $\sigma_{1}$ & $\sigma_{3}$ & $\sigma_{1}$ & $\sigma_{3}$ & $\sigma_{1}$ & $\sigma_{3}$ \\
\hline Sample I & 470.87 & 1.42 & 616.39 & 26.02 & 728.44 & 59.65 & 845.91 & 91.60 & 956.01 & 125.62 \\
\hline Sample II & 473.94 & 2.34 & 619.93 & 27.33 & 732.64 & 60.96 & 850.98 & 93.50 & 960.13 & 127.68 \\
\hline Sample III & 500.09 & 0.91 & 643.09 & 27.89 & 768.84 & 59.21 & 891.96 & 91.01 & 1005.4 & 125.30 \\
\hline Sample IV & 482.55 & 1.96 & 626.30 & 27.93 & 743.76 & 60.64 & 863.97 & 92.65 & 976.05 & 126.74 \\
\hline Sample V & 468.16 & 2.72 & 614.66 & 27.23 & 726.55 & 60.87 & 840.73 & 93.92 & 953.13 & 127.43 \\
\hline
\end{tabular}

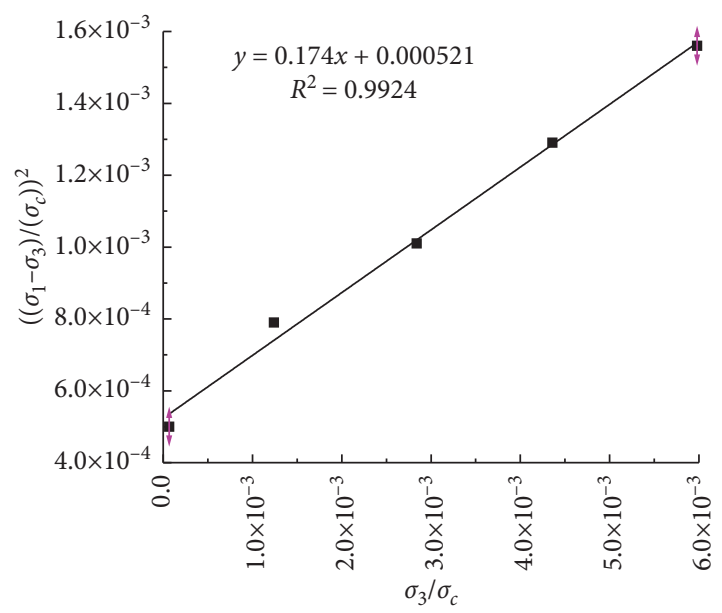

(a)

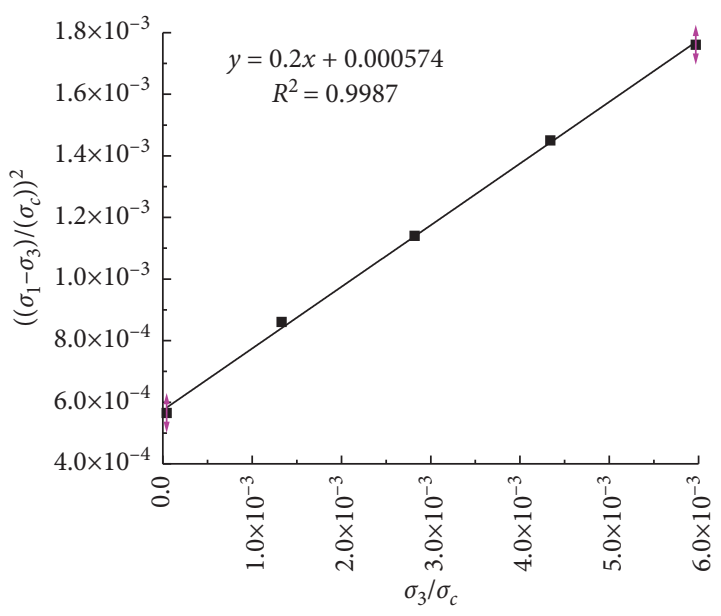

(c)

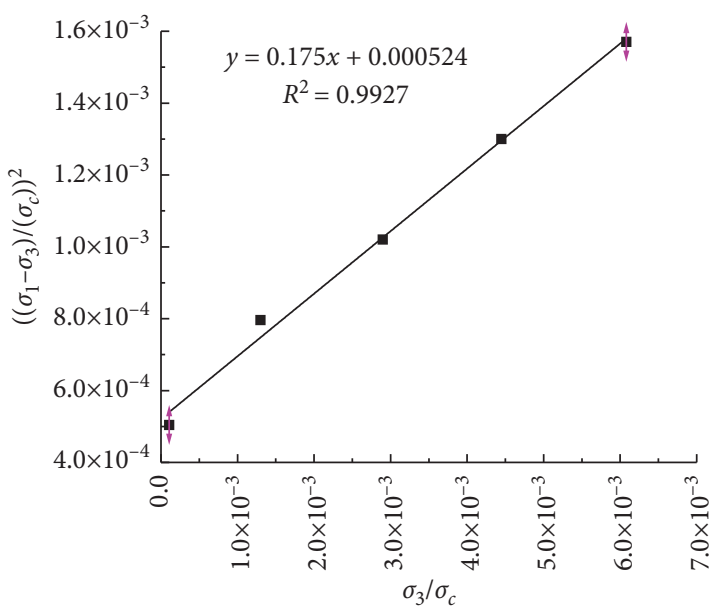

(b)

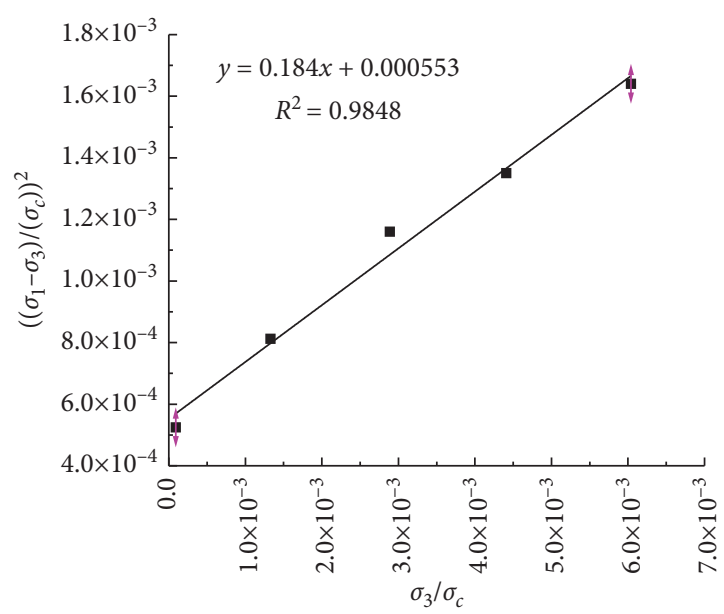

(d)

Figure 7: Continued. 


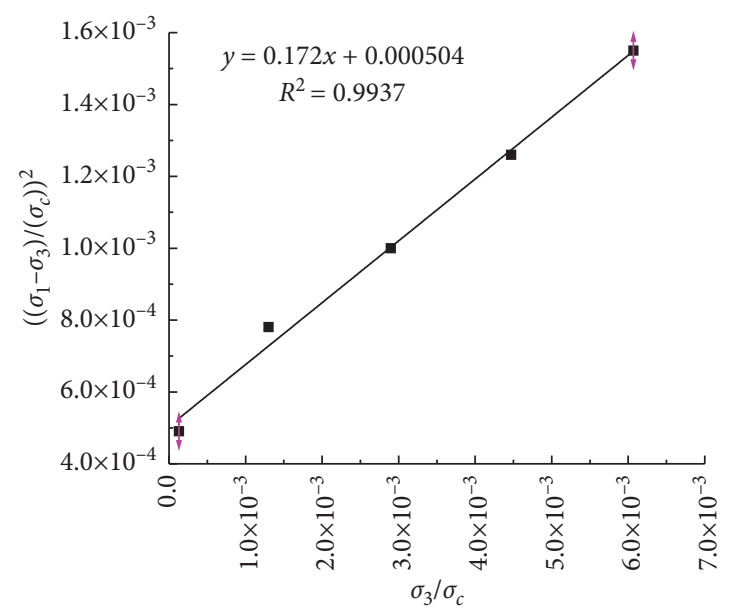

(e)

FIgURE 7: Determination of empirical parameters $m$ and $s$ for each sample. Empirical parameters $m$ and $s$ of (a) sample I, (b) sample II, (c) sample III, (d) sample IV, and (e) sample V.

TAвLE 4: Experience constants and correlation coefficients for each sample determined by shear test.

\begin{tabular}{lccc}
\hline Sample name & Empirical constant $m$ & Empirical constant $s$ & Correlation coefficient \\
\hline Sample I & 0.174 & 0.000521 & 0.9924 \\
Sample II & 0.175 & 0.000524 & 0.9927 \\
Sample III & 0.200 & 0.000574 & 0.9987 \\
Sample IV & 0.184 & 0.000553 & 0.9848 \\
Sample V & 0.172 & 0.000504 & 0.9937 \\
\hline
\end{tabular}

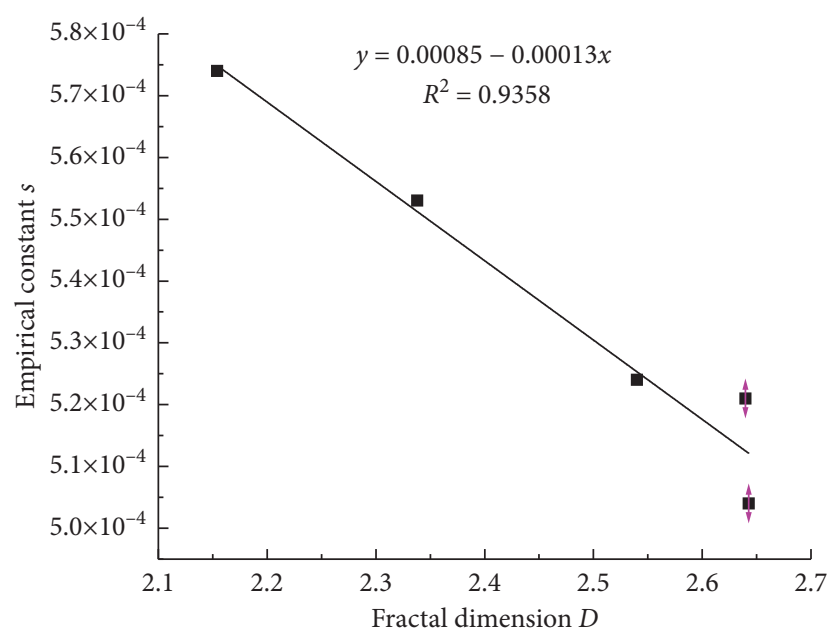

(a)

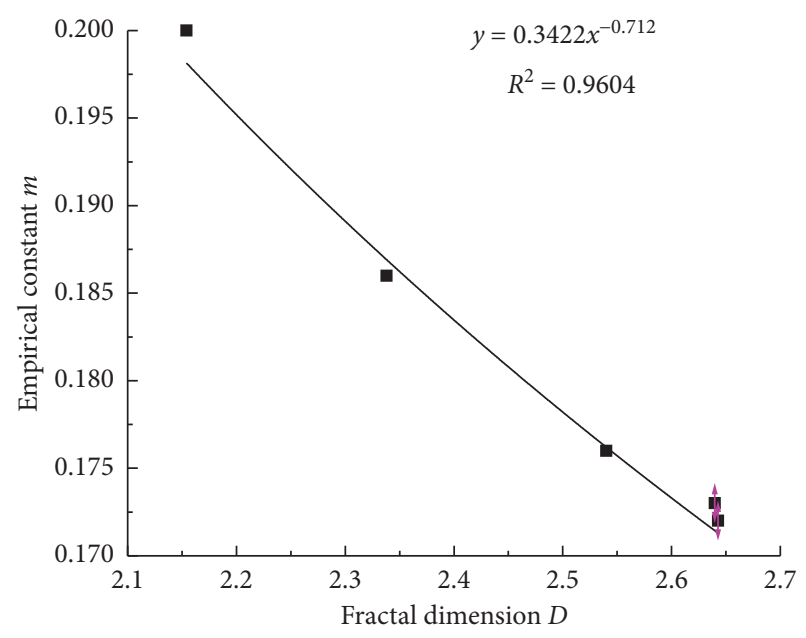

(b)

FIGURE 8: Fractal dimension and empirical parameter relation curve of extremely fractured phyllite at fault fracture zone. (a) Relationship between fractal dimension $D$ and $s$ of extremely fractured phyllite. (b) Relationship between fractal dimension $D$ and $m$ of extremely fractured phyllite. 


\section{Conclusions}

In this paper, field sampling of polar shattered phyllite of different pile numbers in fault fracture zone of Qinyu Tunnel was carried out, and the fractal characteristics of polar broken phyllite were verified by the screening test. Based on fractal theory and large shear test, a method to quantify the empirical strength parameters of polar broken phyllite was established. The specific conclusions are as follows:

(1) Each sample of extremely fractured phyllite with different pile numbers in the fault fracture zone shows good fractal characteristics. The fractal dimension changes from 2.154 to 2.643 . The fractal dimension of different fractal quantification indexes of sample gradation is different, which is manifested as the larger the content of coarse particles, the smaller the fractal dimension.

(2) The closer the gradation of samples is, the smaller the difference of shear strength is. The greater the content of coarse particles, the greater the shear strength of extremely fractured phyllite under the same normal stress condition. The shear strength of extremely fractured surrounding rock is closely related to the grain size characteristics of samples.

(3) The empirical strength parameter $m$ and fractal dimension $D$ of extremely fractured phyllite at fault fracture zone show a good exponential relationship, while the empirical parameter $s$ and fractal dimension $D$ show an excellent linear relationship. Based on the above relationship, the empirical strength parameter can be quantified by the fractal dimension obtained from the field screening test.

(4) In this paper, only the quantitative method for empirical strength parameters of extremely fractured phyllite at fault fracture zone is discussed, the number of samples is limited, and the sampling position is relatively single. Further tests on extremely fractured phyllite at fault fracture zone and analysis of surrounding rocks of different types of fault fracture zone can be carried out, thus expanding the quantitative method for empirical strength parameters of extremely fractured surrounding rocks.

\section{Data Availability}

The data used to support the findings of this study are available from the corresponding author upon request.

\section{Conflicts of Interest}

The authors declare that they have no conflicts of interest regarding the publication of this study.

\section{Acknowledgments}

The project presented in this study was supported by the Natural Science Foundation of China (no. 51778275) and
Longyuan Young Innovative and Entrepreneurial Talents (Team Project no. 2020RCXM120).

\section{References}

[1] E. Hoek and E. T. Brown, "Empirical strength criterion for rock masses," Journal of the Geotechnical Engineering Division, vol. 106, no. 9, pp. 1013-1035, 1980.

[2] E. Hoek and E. T. Brown, Underground Excavation in rock, Austin \& Sona Ltd, Hertford, UK, 2nd edition, 1988.

[3] E. Hoek, "Strength of rock and rock masses," International Society for Rock Mechanics News Journal, vol. 2, no. 2, pp. 4-16, 1994.

[4] E. Hoek, C. Carranze-Toress, and B. Corkum, "Hoek-Brown failure criterion-2002 edition," in Proceeding of the North American Rock Mechanics Society Meeting, pp. 267-273, Toronto, July 2002.

[5] T. Maolin, H. Lijun, and M. Qingbin, "Nonlinear regression analysis for deep rock mass parameters of the hoek-brown failure criterion based on the differential evolution," KSCE Journal of Civil Engineering, vol. 25, pp. 3160-3171, 2021.

[6] X.-L. Yang, "Seismic displacement of rock slopes with nonlinear Hoek-Brown failure criterion," International Journal of Rock Mechanics and Mining Sciences, vol. 44, no. 6, pp. 948-953, 2007.

[7] A. J. Li, R. S. Merifield, and A. V. Lyamin, "Stability charts for rock slopes based on the Hoek-Brown failure criterion," International Journal of Rock Mechanics and Mining Sciences, vol. 45, no. 5, pp. 689-700, 2008.

[8] K. Jyant and R. Obaidur, "Lower bound limit analysis of unsupported vertical circular excavations in rocks using Hoek-Brown failure criterion," International Journal for Numerical and Analytical Methods in Geomechanics, vol. 44, no. 7, 2020

[9] Xu Jiang, D. Guoliang, and G. Weiming, "Elastoplastic analysis of normal stiffness of bore wall of the rock-socketed pile based on Hoek-Brown failure criterion and cavity expansion theory," Japanese Geotechnical Society Special Publication, vol. 8, no. 7, 2020.

[10] K. W. John, "An approach to rock mechanics," Journal of the Soil Mechanics and Foundations Division, vol. 88, no. 4, pp. 1-30, 1962.

[11] E. Hoek, "Strength of jointed rock masses," Géotechnique, vol. 33, no. 3, pp. 187-223, 1983.

[12] E. Hoek and E. T. Brown, "Practical estimates of rock mass strength," International Journal of Rock Mechanics and Mining Sciences, vol. 34, no. 8, pp. 1165-1186, 1997.

[13] X.-L. Yang and J.-H. Yin, "Slope equivalent mohr-coulomb strength parameters for rock masses satisfying the hoekBrown criterion," Rock Mechanics and Rock Engineering, vol. 43, no. 4, pp. 505-511, 2010.

[14] J. L. Justo, E. Justo, J. M. Azañón, P. Durand, and A. Morales, "The use of rock mass classification systems to estimate the modulus and strength of jointed rock," Rock Mechanics and Rock Engineering, vol. 43, no. 3, pp. 287-304, 2010.

[15] E. Eberhardt, "The Hoek-Brown failure criterion," Rock Mechanics and Rock Engineering, vol. 45, no. 6, pp. 981-988, 2012.

[16] H. Sonmez and R. Ulusay, "Modifications to the geological strength index (GSI) and their applicability to stability of slopes," International Journal of Rock Mechanics and Mining Sciences, vol. 36, no. 6, pp. 743-760, 1999.

[17] M. Cai, P. K. Kaiser, H. Uno, Y. Tasaka, and M. Minami, "Estimation of rock mass deformation modulus and strength 
of jointed hard rock masses using the GSI system," International Journal of Rock Mechanics and Mining Sciences, vol. 41, no. 1, pp. 3-19, 2004.

[18] G. Jiang, N. Hu, G. Hong, and G. Li, "Determination of rock mass mechanical parameters based on quantification and correction method of GSI value," Rock and Soil Mechanics, vol. 39, no. 6, pp. 2211-2218, 2018.

[19] S. W. Tyler and S. W. Wheatcraft, "Fractal scaling of soil particle-size distributions: analysis and limitations," Soil Science Society of America Journal, vol. 56, no. 2, pp. 362-369, 1992.

[20] P. Yang, Y. Luo, and Y. Shi, "Fractal characteristics of soil characterized by weight distribution of particle size," Chinese Science Bulletin, vol. 38, no. 20, pp. 1896-1899, 1993.

[21] S. Ben, Specification for Coarse Grained Soil Test of Hydropower and Water Conservancy Projects, China Electric Power Press, Beijing, China, 2007. 